\title{
PHOTOGRAMMETRY-DERIVED ORTHOIMAGERY AND ELEVATION FOR KOTLIK, ALASKA, COLLECTED JULY 9-10, 2021
}

Richard M. Buzard, Jessica E. Christian, and Jacquelyn R. Overbeck

Raw Data File 2021-16
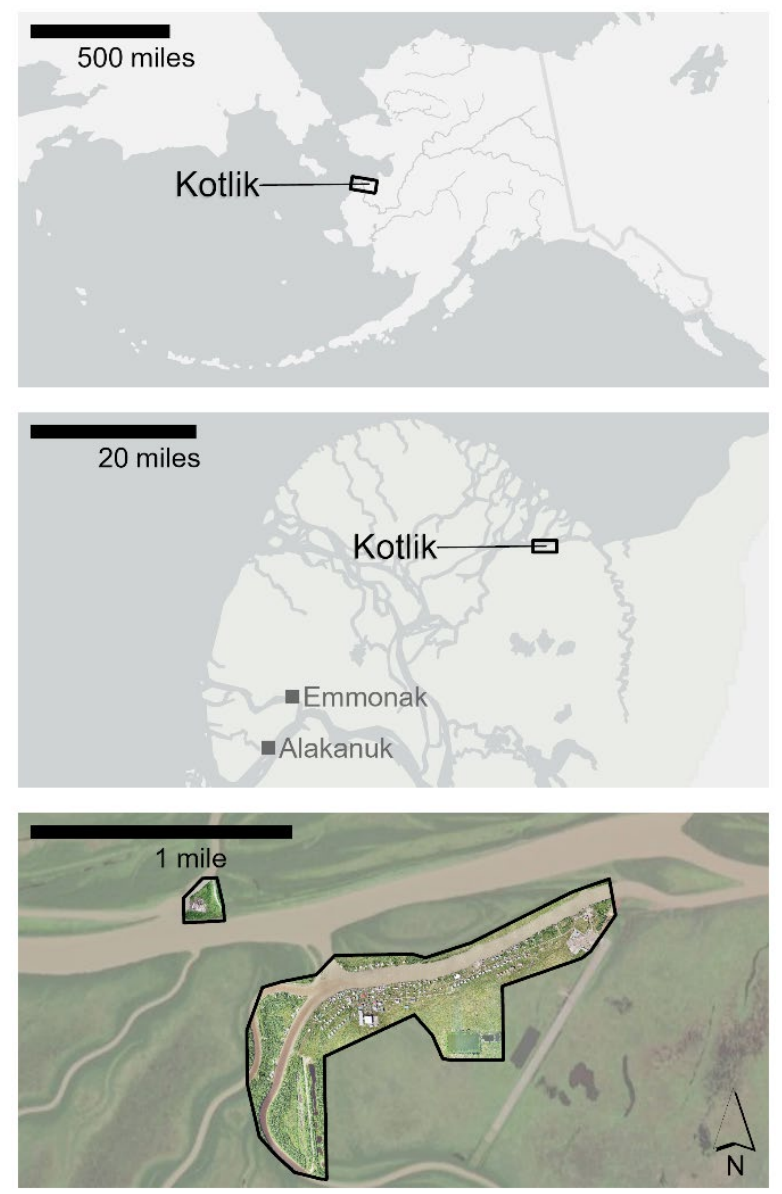

Location map of survey area with orthoimage.

This report has not been reviewed for technical content or

for conformity to the editorial standards of DGGS.

2021

STATE OF ALASKA

DEPARTMENT OF NATURAL RESOURCES

DIVISION OF GEOLOGICAL \& GEOPHYSICAL SURVEYS
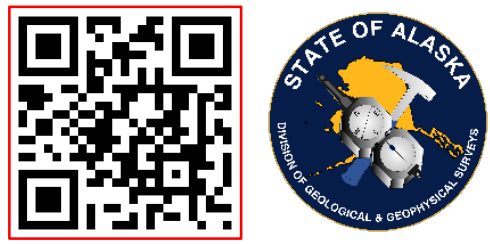


\section{STATE OF ALASKA}

Mike Dunleavy, Governor

\section{DEPARTMENT OF NATURAL RESOURCES}

Corri A. Feige, Commissioner

\section{DIVISION OF GEOLOGICAL \& GEOPHYSICAL SURVEYS}

Steve Masterman, State Geologist \& Director

Publications produced by the Division of Geological \& Geophysical Surveys are available to download from the DGGS website (dggs.alaska.gov). Publications on hard-copy or digital media can be examined or purchased in the Fairbanks office:

\section{Alaska Division of Geological \& Geophysical Surveys (DGGS)}

3354 College Road | Fairbanks, Alaska 99709-3707

Phone: 907.451 .5010 | Fax 907.451.5050

dggspubs@alaska.gov | dggs.alaska.gov

DGGS publications are also available at:

Alaska State Library, Historical

Collections \& Talking Book Center

395 Whittier Street

Juneau, Alaska 99801

Alaska Resource Library and

Information Services (ARLIS)

3150 C Street, Suite 100

Anchorage, Alaska 99503

\section{Suggested citation:}

Buzard, R.M., Christian, J.E., and Overbeck, J.R., 2021,

Photogrammetry-derived orthoimagery and elevation for Kotlik,

Alaska, collected July 9-10, 2021: Alaska Division of Geological \& Geophysical Surveys Raw Data File 2021-16, 5 p.

https://doi.org/10.14509/30789

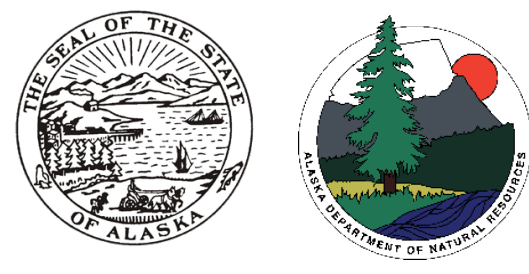




\section{PHOTOGRAMMETRY-DERIVED ORTHOIMAGERY AND ELEVATION FOR KOTLIK, ALASKA, COLLECTED JULY 9-10, 2021}

Richard M. Buzard ${ }^{1}$, Jessica E. Christian², and Jacquelyn R. Overbeck ${ }^{1}$

\section{INTRODUCTION}

The State of Alaska Division of Geological \& Geophysical Surveys (DGGS) collected low-altitude aerial images from an unmanned aerial vehicle (UAV) on July 9-10, 2021 and used Structure-from-Motion (SfM) photogrammetry to produce a digital surface model (DSM) and orthoimage of Kotlik (fig. 1). The orthoimagery and elevation data are for assessing coastal hazards and changes. We used Trimble Business Center to process the Global Navigation Satellite System (GNSS) data used for positional control. We used Agisoft Metashape to process the photogrammetry data. These products are released as a Raw Data File with an open enduser license. All files can be downloaded from doi.org/10.14509/30789 or elevation.alaska.gov.

\section{LIST OF DELIVERABLES}

- Orthoimagery

- Digital Surface Models (DSM)

- Metadata
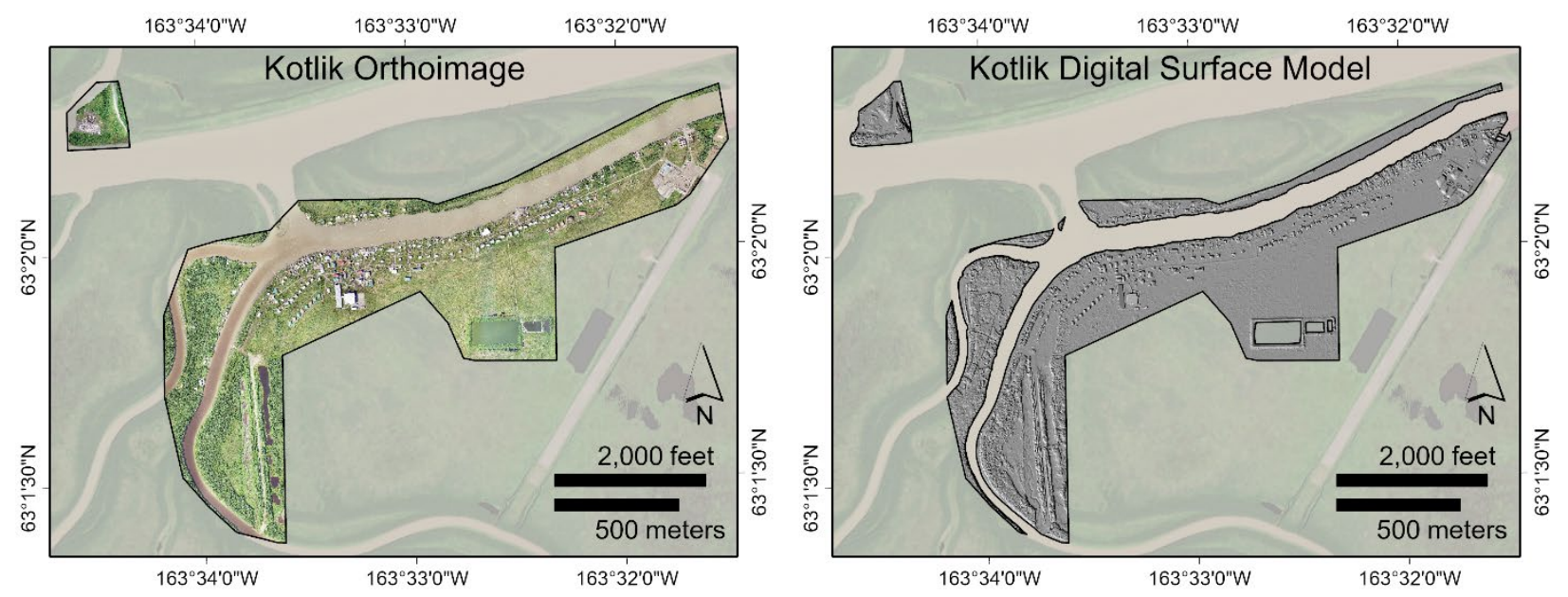

Figure 1. Extent of orthoimagery (left) and DSMs (right) for Kotlik.

\footnotetext{
${ }^{1}$ Alaska Division of Geological \& Geophysical Surveys, 3354 College Road, Fairbanks, AK 99709.

${ }^{2}$ University of Alaska Fairbanks Arctic Coastal Geoscience Lab, P.O. Box 755780, Fairbanks, AK 99775.
} 


\section{MISSION PLAN}

\section{Aerial Photogrammetric Survey Details}

DGGS used a DJI Phantom 4 RTK UAV with a FC6310R camera model (8.8 mm lens) to collect 20-megapixel JPEG photographs ( $5472 \times 3648$ pixels per image). We conducted two separate surveys: one over the city and one at the landfill. We flew the aerial surveys with 70 percent sidelap, 80 percent frontlap, and nadir camera orientation stabilized by a 3axis gimbal. The city survey was flown $120 \mathrm{~m}$ above the ground at $7.9 \mathrm{~m} / \mathrm{s}$. The landfill survey was flown $100 \mathrm{~m}$ above the ground at $6.5 \mathrm{~m} / \mathrm{s}$. The resulting images cover $1.45 \mathrm{~km}^{2}$ with ground sampling distance (GSD) of approximately $0.03 \mathrm{~m}$.

\section{Weather and Photo Conditions}

DGGS conducted the landfill flight on July 9, 2021, from 10:15 to 10:30 AM AKDT, and the city flight on July 10,2021, from 4:45 to 7:30 PM AKDT. During the city survey, the operator returned the UAV five times to change batteries. The weather throughout both surveys was fair with scattered clouds, no rain, and light wind. No abnormalities were observed during the flights.

\section{SURVEY AND PROCESSING REPORT}

\section{Ground Survey Details}

DGGS set up a GNSS base station using a Trimble R10 receiver sampling at $5 \mathrm{~Hz}$. The base was installed over a benchmark with a published solution (found at www.ngs.noaa.gov/OPUS/getDatasheet.jsp?PID=BBGX51). This provided real-time kinematic (RTK) corrections to the Trimble R8s GNSS receiver. DGGS measured 18 photo-identifiable points with the R8s. We later derived the corrected base position using the Online Positioning User Service (found at www.ngs.noaa.gov/OPUS/) and post-processed the R8s positions in Trimble Business Center.

\section{Photogrammetric Dataset Processing}

The UAV did not maintain RTK connection with the Trimble R10 base station. We apply a post-processing kinematic correction using RTKLIB (an open-source GNSS processing software found at www.rtklib.com). The UAV GNSS receiver samples at $5 \mathrm{~Hz}$, rather than at image acquisition times. We interpolate the corrected positions at image timestamps to derive coordinates. The image timestamp metadata also contains orientation to support the lever arm correction that adjusts coordinates from the GNSS receiver to the camera. We compute the interpolation and lever arm correction using the worksheet found at www.aerotas.com/phantom4-rtk-ppk-processing-workflow.

DGGS processed images in Agisoft Metashape Professional software (Version 1.6.3 build 10732). We masked image corners where shadows and image warping were disruptive. Processing steps included aligning images, identifying ground control points (GCPs), manually cleaning the sparse point cloud, optimizing the bundle block adjustment (refining camera positions and lens distortion parameters), constructing the dense point cloud, building the DSM, and creating the orthomosaic image. We used six GCPs to create the model, leaving twelve survey check points.

We processed the landfill separately and obtained no points to georeference or check the raw output. We shift the products in X, Y, and Z to fit the 2019 lidar-derived DSM 
(available for download at elevation.alaska.gov). The horizontal shift is accomplished with one reference point (no rotation or rescale required). The vertical shift is calculated using the median offset of the DSMs in bare earth areas. This offset includes the correction from ellipsoid to orthometric height.

\section{Orthoimagery}

The orthoimagery is a three-band (red, green, blue) 8-bit unsigned GeoTIFF file with the "No Data" value set to 0 . The city orthoimage has a GSD of $0.033 \mathrm{~m}$ per pixel. The landfill orthoimage has a GSD of 0.028 m per pixel.

\section{Digital Surface Model}

The DSM represents surface elevations such as the height of vegetation and buildings. Water bodies introduce noise. We manually delineate the river boundary to restrict the DSM to the land. We selectively remove areas where inland water bodies introduced great noise. The DSM is a single-band, 32-bit floating point GeoTIFF file with the "No Data" value set to $3.4028231 \times 10^{38}$. The city DSM has a GSD of $0.066 \mathrm{~m}$. The landfill DSM has a GSD of $0.055 \mathrm{~m}$.

\section{ACCURACY REPORT}

\section{Coordinate System and Datum}

All data are processed and delivered in NAD83 (2011) UTM Zone 3N and vertical datum NAVD88 (GEOID12B).

\section{Horizontal Accuracy}

We quantify the horizontal accuracy of the city DSM and orthoimage by comparing the known locations of 12 photo-identifiable check points measured with GNSS against their modeled locations in the photogrammetric products (fig. 2). X and Y errors are calculated as the root-mean-square (RMS) error of offsets. The total horizontal error is the root-sumsquare error of $X$ and Y RMS errors, $0.048 \mathrm{~m}$ (table 1).

Horizontal accuracy of the landfill DSM and orthoimage is not assessed.

\section{Vertical Accuracy}

We assess vertical accuracy of the city DSM using the same twelve check points. The RMS error of $\mathrm{Z}$ offsets is $0.070 \mathrm{~m}$ (table 1 ). The total error of the DSM (X, Y, and Z) is 0.085 m.

We assess vertical accuracy of the landfill DSM using the fit to the lidar (control) DSM. The lidar non-vegetated vertical accuracy is $0.082 \mathrm{~m}$ (Herbst and Daanen, 2020). The RMS error of the vertical correction is $0.153 \mathrm{~m}(\mathrm{n}=22,401)$. The total error is $0.173 \mathrm{~m}$ (root-sumsquare error of the control and fit RMS errors). 


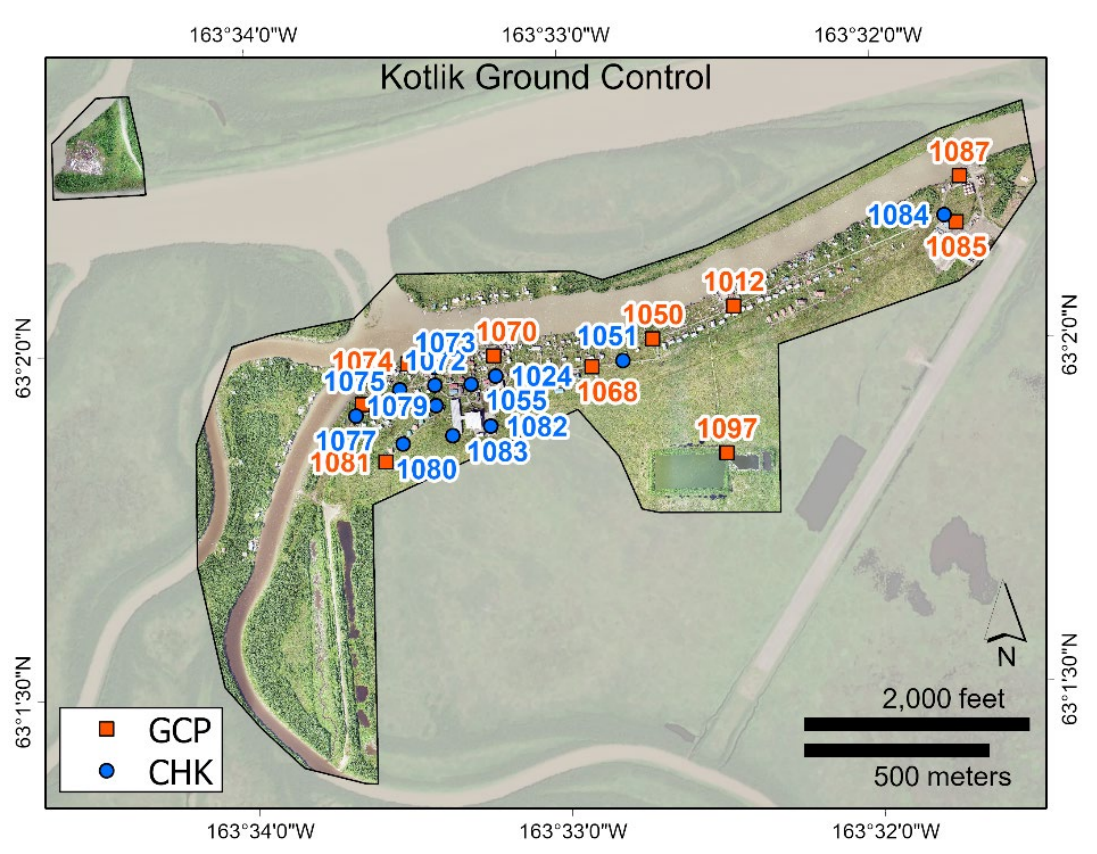

Table 1. Check point coordinates and offsets from city orthoimage and DSM.

\begin{tabular}{|c|c|c|c|c|c|c|}
\hline Check Point & Easting & Northing & Elevation & X Offset (m) & Y Offset (m) & Z Offset (m) \\
\hline 1024 & 573177.772 & 6990050.854 & 3.028 & 0.011 & 0.001 & 0.012 \\
\hline 1051 & 573521.721 & 6990092.748 & 2.645 & -0.047 & 0.020 & 0.128 \\
\hline 1055 & 573112.093 & 6990028.673 & 3.387 & -0.033 & 0.054 & -0.028 \\
\hline 1072 & 573014.123 & 6990025.893 & 3.205 & 0.006 & 0.026 & -0.043 \\
\hline 1073 & 573013.309 & 6990074.642 & 3.422 & 0.037 & 0.014 & -0.046 \\
\hline 1075 & 572919.292 & 6990013.547 & 3.621 & -0.014 & 0.032 & -0.108 \\
\hline 1077 & 572800.873 & 6989942.880 & 3.109 & 0.003 & -0.002 & -0.103 \\
\hline 1079 & 573017.496 & 6989970.247 & 2.960 & 0.000 & 0.026 & -0.044 \\
\hline 1080 & 572928.491 & 6989867.305 & 3.094 & 0.001 & 0.040 & -0.083 \\
\hline 1082 & 573165.162 & 6989915.292 & 3.146 & 0.035 & 0.080 & 0.005 \\
\hline 1083 & 573062.084 & 6989890.103 & 3.602 & 0.021 & 0.066 & 0.026 \\
\hline 1084 & 574387.580 & 6990486.446 & 4.023 & -0.012 & -0.054 & -0.071 \\
\hline & & & Mean & 0.001 & 0.025 & -0.030 \\
\hline & & & Standard Deviation & 0.025 & 0.035 & 0.066 \\
\hline & & & Range & 0.084 & 0.134 & 0.236 \\
\hline & & & Root Mean Square Error & 0.024 & 0.042 & $\mathbf{0}$ \\
\hline & & & Total Error & & $\mathbf{0 . 0 4 8}(\mathbf{X Y})$ & $\mathbf{0 . 0 8 5}$ (XYZ) \\
\hline
\end{tabular}




\section{Data Consistency and Completeness}

DGGS visually inspected the orthoimage for data errors such as shifts, seamline mismatches, and water noise overlapping land. There were no significantly erroneous areas that required repair. Visual errors common to these SfM photogrammetry products include discontinuous powerlines, blurriness near high-angle features like buildings, and distortion at water boundaries. Bright objects like metal roofs and white paint can cause overexposure, leading to spurious elevation points.

\section{ACKNOWLEDGEMENTS}

We thank the Native Village of Bill Moore's Slough for funding and supporting the creation of these data products. 